\title{
Can cognitive maps provide insight into women who hurt their children?
}

\author{
Marie E. Mugavin , Robert E. Sapien \\ Department of Emergency Medicine, School of Medicine, University of New Mexico, New Mexico, United States
}

Received: February 15, 2016

Accepted: June 29, 2016

Online Published: August 1, 2016

DOI: $10.5430 /$ jnep.v6n12p71

URL: http://dx.doi.org/10.5430/jnep.v6n12p71

\begin{abstract}
Efforts to organize information relative to complex, multifaceted issues such as fatal and nonfatal child abuse can be daunting but are essential to the development of adequate strategies for recognition of at-risk mothers and, ultimately, for prevention-focused interventions. The purpose of this exploratory descriptive pilot study using quantitative and qualitative techniques was to determine what constellation of antecedents broadly categorized as vulnerabilities and triggers may be associated with fatal or nonfatal abuse from the viewpoint of the mother/perpetrator. Due to challenges in accessing the study population, a convenience sample of 88 women incarcerated for fatal and nonfatal abuse was drawn from four women's prisons in three Southwestern United States. A structured questionnaire consisting of 68 paired comparisons was administered to participants. Participants rated the vulnerabilities and triggers for dissimilarity and ranked their relative importance. Priority ratings were obtained from responses to content analysis questions. Multidimensional scaling (MDS) and clustering methodologies were used to generate cognitive maps of the concepts in relation to one another. The two groups shared common underlying structures consisting of three disparate clusters, "Family Intimacy", "Negative Emotion", and "Abuse". They diverged in vulnerabilities and triggers that had the most profound impact on their thinking and behavior. Both groups had a similar underlying structure for antecedents to these crimes, but evaluative responses showed differences between women convicted of fatal versus nonfatal abuse.
\end{abstract}

Key Words: Child abuse, Filicide, Multidimensional scaling, Cognition

\section{INTRODUCTION}

Evidence supports that most humans perceive and organize information, make and execute decisions, and learn without awareness. Cognitive scientists explore processes such as perceptual organization, classification, learning, memory to problem solve and to advance knowledge. ${ }^{[1]}$ Efforts to organize information relative to complex, multifaceted issues such as fatal and nonfatal child abuse can be daunting. Thus far, categorization of women who kill (filicide) or abuse their children reflects the offender's psychopathology, social and psychiatric stress factors, the source of impulse to kill, and the suspect's alleged motive for the crime. ${ }^{[2-5]}$ For the purposes of this paper, fatal abuse will be used interchangeably with filicide and nonfatal abuse with abuse.

The literature deliberating a cognitive approach to child abuse is complex and informative. A brief overview will be provided to bring context to the discussion; exploring its full depth and breadth is beyond the scope of this paper. Internal working models (or schema) are one conceptual underpinning of cognitive approaches to child abuse. These models explore basic explicit parent-child dynamics by considering their implicit origins; they focus on aspects of cognition that

\footnotetext{
*Correspondence: Marie E. Mugavin; Email: memugavin@ salud.unm.edu; Address: Department of Emergency Medicine, School of Medicine, University of New Mexico, New Mexico, United States.
} 
operate at a subconscious, automatic level and as functions of early experience. Internal working models (IWM) become scripted or schematic accounts and act as organizers of expectations and guides to behavior. ${ }^{[6-9]}$

The social information processing model (SIP) developed by Farc, Skowronski \& Milner ${ }^{[10]}$ contends that abusive parents process social information differently than nonabusive parents. SIP combines psychological and social elements believed to shape parenting behaviors. The authors suggest that pre-existing schemas, parental moods, and situational contexts influence conduct. For instance, characteristics within the abusive individual such as parenting beliefs and depression, when exacerbated by social stressors (i.e., poverty and a fragmented support system), predispose to aggressive behavior toward their child. Bugental \& Johnson ${ }^{[11]}$ contemplated cognitions of the parent-child dyad developed in the context of the family as a social network. Described are how interfamilial dynamics link to affect and behavior and how transmission, negotiation, and renegotiation of cognitions occurs between family members.

Parental foresight and its implications for intervention in both child maltreatment and childhood injury were brought to the forefront by Azar \& Weinzieri. ${ }^{[12]}$ The authors used constructs from human information processing theory to explain errors in parental judgment that increase child risk. Discussed are factors that may explain parental maladaptive schema, executive functioning problems, and maladaptive appraisals. Seng \& Prinz ${ }^{[13]}$ focused on a broader ecological context. While cognitions may occur at an individual level they are shaped in part by interpersonal, intrapersonal, direct and indirect environmental factors. Maladaptive cognitions were thought to be associated with IWMs constructed during formative years and with deficits in personal, family, community and societal levels.

Healthcare providers engage individuals in all of these domains (personal, family, community, and social) and can play a vital role in the identification and assessment of at-risk women. Literature reflects that several mothers who committed filicide and abuse reported having had contact with clinicians or therapists 48 hours to 2 weeks prior to hurting their children. ${ }^{[3,4,14-16]}$ Identification of women at risk for these crimes is challenging, making prevention difficult. ${ }^{[2,16]}$ The generation of cognitive maps of perpetrator narrated risk factors, we sought to detect how specific or groups of risk factors identify common versus idiosyncratic positioning.

\section{Conceptual framework}

The Maternal Filicide Theoretical Framework (MFTF) was used as the theoretical basis for this pilot study which posits that exposure to childhood trauma influences an individual's future behavior and can increase the potential for abuse to be carried forward to the next generation. ${ }^{[17]}$ The MFTF was informed by family systems theory, attachment theory and propositions from the neurobiology and neurodevelopment of trauma literature. Broad cognitive categories called vulnerabilities and triggers are used in the framework. Vulnerabilities are biopsychosocial factors produced by the interaction of the genotype and the environment that give rise to differences among individuals. ${ }^{[16]}$ Examples of vulnerabilities include a family history of psychiatric illness, exposure to substance abuse, and a history of physical and/or sexual abuse and neglect. Triggers are defined as stimuli that initiate an action, process, or series of events. ${ }^{[16,18-20]}$ Examples of triggers in the context of filicide and abuse are the stress of trying to be a good mother without the benefit of adequate role modeling or social support, fear, desperation, substance abuse and revenge. Genetic and environmental vulnerabilities can predispose to certain triggers particularly if the women were not exposed to a reparative environment during formative years. ${ }^{[21,22]}$

Emphasized in the framework is that a woman's attachment experience is significantly linked to her capacity to assume the maternal role. ${ }^{[6,16]}$ Early life attachment experiences become enduring IWM, which encode coping strategies and basic regulation in the face of environmental challenges. ${ }^{[14,15]}$ Trauma affects the key regulatory processes that control memory, aggression, attachment, and emotion. ${ }^{[15,16]}$ Cognitively at-risk mothers show the highest level of physiological reactivity to potentially difficult interactions with their children. One possible outcome is an inability to regulate impulse and emotion with implications affecting later social conduct. There may be an instant exaggerated threat response to minor stimuli that effectively reactivates previously sensitized neural networks. ${ }^{[15,16]}$ Items used in the present study questionnaire were based on the vulnerability and trigger components of the framework because they are considered most relevant to the development of adequate strategies for recognition of mothers at risk and, ultimately, for prevention-focused interventions.

\section{MeThODS}

\subsection{Research design}

The purpose of this exploratory, descriptive study was to determine what constellation of vulnerabilities and triggers may be associated with filicide or nonfatal abuse from the viewpoint of the mother. Discriminating characteristics between women who commit filicide and those women who abuse their children were explored. Both quantitative and qualitative techniques were used to answer the research ques- 
tions: (1) Can cognitive maps demonstrate how this sample of women organize their thoughts relative to vulnerabilities and triggers that anteceded their crime? (2) Do the two groups evaluate the relative importance of the vulnerabilities and triggers differently? We used psychometric scaling procedures and clustering to describe implicit cognitive structures or schema in the respondent's perceptual "space" by asking them to rate how similar or different pairs of potentially relevant concepts are. Through multidimensional scaling procedures (MDS) we generated cognitive maps of concepts in that perceptual space through detection of the implicit schema concerning vulnerabilities and triggers.

Cognitive maps, however, do not capture how subjects evaluate the survey items; two women may agree about the types and characteristics of abuse, however, one might believe that physical abuse is inherently wrong, humiliating, and dangerous, whereas the other might consider it not especially harmful or even, in some contexts, a good thing in that it promotes discipline and self-control. The same perception can lead to different evaluations, and hence to markedly different outcomes. To capture this, priority ratings were obtained from responses to content analysis questions.

\subsection{Setting and sample}

The study took place in four women's prisons in three Southwestern states in the United States. Perpetrators who were the biological mothers, stepmothers, and grandmothers of the children were included. Women who spoke Spanish exclusively were excluded. Mean age of the women at the time of participation in the study was 29 with a range from 26-33 years of age. One hundred and two met the legal burden of psychiatric competence for the purpose of standing trial and who have been adjudicated and sentenced with their cases no longer under appeal were eligible to participate in the study. Forty-three were incarcerated for convictions stemming from the filicide of their children. The mean age of children at the time of their deaths ranged from newborn to 14 years. Forty-five of the women were incarcerated for convictions of child abuse (negligently caused or intention, but not resulting in death or great bodily harm). The age of the children abused ranged from newborn to 18 years of age. Charges for this sample of women varied from cruelty and felony child endangerment to first-degree murder and sentences ranged from 18-months to life in prison.

\subsection{Procedure}

The protocol was approved by the Department of Corrections Internal Review Boards, in the prisons and by the University Human Research Review Board. Two attorneys were consulted to ensure the study was in compliance with the
Federal Guidelines and the protective measures put in place were in accordance with the National Academy of Sciences Ethical Considerations for Research Involving Prisoners. ${ }^{[23]}$ All participants provided informed consent. The study was introduced to the inmates by their case managers who were provided in-depth training by the principal investigator so introductions were consistent. Person-to-person interviews were conducted with participants by the primary author. If the inmate agreed to participate, she met with the investigator, was consented, and completed the demographic form and a questionnaire. Interview sessions averaged 90-120 minutes. Participants read a set of standardized instructions and reviewed two "practice" items to ensure that the instructions were understood before proceeding with the comparisons.

\subsection{Measures}

A demographic form and the Similarity Judgment Scale (SJS) ${ }^{[24]}$ were used in this investigation. The SJS developed for the purposes of this project, was a survey that solicited the participants to make dissimilarity comparisons between pairs of concepts associated with the perceived vulnerabilities and triggers that were present antecedent to the crime. The order of the survey concept presentation in the SJS was random. A survey concept in this context is a psychological trait, such as "revenge", "desperate", or "rejected". A modified version of Lynn's ${ }^{[25]}$ content validity strategy was used to determine how the individual survey concepts might be best presented to the participant. The goal was to approximate a 7th-grade reading level using the Fry Readability Scale. The concepts were derived from peer-reviewed literature and required rewording in order to be more readily understood by the participants.

The concepts employed were also evaluated by a group of five professionals, including an adult/adolescent psychiatrist, a child psychiatrist, a prison administrator, an advanced practice forensic psychiatric nurse, and a registered nurse with 30 years of psychiatric nursing experience. Five women hospitalized on a psychiatric unit over a 12-week period, who were stabilized on medication and who had a history of perpetrating child abuse or attempting child murder were also shown the concepts/phrases for suggestions as to how to make the items more easily understandable for study participants. They were then refined and arranged in a suitable sequence. Once the survey was assembled, the judgmentquantification stage was embarked upon.

Subjects were asked to express the dissimilarity of two concepts by a number. In other words, to rate how similar or different the two items presented were to the participants. An 8-point scale was used, with a low number indicating a strong dissimilarity and a high number indicating strong similarity 
between two concepts. It was determined that presenting all unique combinations of 12 stimuli (see Table 1) was not cognitively taxing. In addition to the 66 unordered pairwise similarity judgments of the 12 items $(12(12-1) / 2=66)$, two additional repeated items were used to assess stability, giving a total of 68 ratings that were presented in random order to the participants to avoid presentation order effects. ${ }^{[26]}$ Each woman was reassured that there were no right or wrong answers (as motivated subjects may worry they are not "doing it right"). Cognitive maps were then generated using MDS and clustering procedures (see Figure 1).

Table 1. List of stimuli

\begin{tabular}{ll}
\hline Vulnerabilities & Triggers \\
\hline Sexual abuse & Revenge \\
Alcohol/drug use & Told by God \\
Physical abuse & Being a good mom \\
Close to your mom & Desperate \\
Close to your children & Rejected \\
& Fear \\
& Misbehave \\
\hline
\end{tabular}

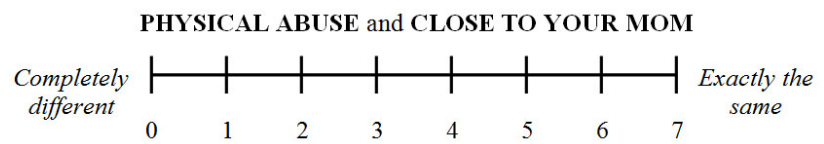

Figure 1. Similarity judgment scale, example of pairwise comparisons

Evaluative information was drawn from participant responses to content analysis questions. An example of a content analysis question is: Please list the top three concepts (from the list of 12) you feel had the most profound impact on your thinking and behavior. Participant definitions of the concepts were remarkably similar but due to page constraints this information will not be included in the discussion.

\subsection{Data analysis}

Demographic data were entered into PASW software. Descriptive statistics were used to characterize the sample. The items rated for similarity were analyzed using multidimensional scaling software. The initial focus was the group level (aggregate) data.

Responses to the content analysis questions were ranked in relative importance and scored inversely. Test-retest. Intraclass correlation coefficient was estimated across subjects, and percent agreement was determined for the two redundant pairwise comparisons randomly placed within the questionnaire.

\section{RESULTS}

Demographic characteristics of the participants and the victims are shown in Table 2. Characteristics of the sample were relatively uniform. Of note, $40 \%$ of those incarcerated for filicide had an average of 2-4 years of college education whereas $56 \%$ of those women incarcerated for abusing their children did not graduate high school. There were no statistically significant differences between women of different ethnicities. The majority of filicides were reported to be impulsive responses to various stressors with only 2 women in the group reporting the deaths of their children were the result of long-term abuse.

Table 2. Demographic characteristics of the sample

\begin{tabular}{|c|c|c|}
\hline Demography & $\begin{array}{l}\text { Filicidal Mothers } \\
\mathrm{N}=43\end{array}$ & $\begin{array}{l}\text { Abusive Mothers } \\
\mathrm{N}=45\end{array}$ \\
\hline \multicolumn{3}{|l|}{ Relationship to child } \\
\hline Biological Mother & 40 & 41 \\
\hline Stepmother & 3 & 3 \\
\hline Grandmother & 0 & 1 \\
\hline \multicolumn{3}{|l|}{ Age } \\
\hline Age at incarceration/mean & 26 & 29 \\
\hline Age at interview/mean & 33 & 38 \\
\hline \multicolumn{3}{|l|}{ Ethnicity } \\
\hline Anglo & $42 \%$ & $22 \%$ \\
\hline Hispanic & $37 \%$ & $56 \%$ \\
\hline African American & $18 \%$ & $11 \%$ \\
\hline Other & $3 \%$ & $11 \%$ \\
\hline \multicolumn{3}{|l|}{ Religion } \\
\hline Christian & $80 \%$ & $74 \%$ \\
\hline Catholic & $11 \%$ & $15 \%$ \\
\hline Buddhist & $2 \%$ & $0 \%$ \\
\hline Wiccan & $1 \%$ & $2 \%$ \\
\hline None listed & $6 \%$ & $9 \%$ \\
\hline \multicolumn{3}{|l|}{ Marital Status } \\
\hline Single & $42 \%$ & $33 \%$ \\
\hline Married/Cohabitation & $35 \%$ & $33 \%$ \\
\hline Divorced & $23 \%$ & $33 \%$ \\
\hline \multicolumn{3}{|l|}{ Education } \\
\hline$<12^{\text {th }}$ Grade & $30 \%$ & $56 \%$ \\
\hline$=12^{\text {th }}$ Grade & $30 \%$ & $44 \%$ \\
\hline$>12^{\text {th }}$ Grade & $40 \%$ & $0 \%$ \\
\hline \multicolumn{3}{|l|}{ Prison Information } \\
\hline Prison time served/mean & 3 years & 3 years \\
\hline Prison time remaining/mean & 11 years & 14 years \\
\hline \multicolumn{3}{|l|}{ Characteristics of Victims } \\
\hline Number of Children & 71 killed & 197 abused \\
\hline \multirow{3}{*}{ Age of Children } & 59 ( 0 -3 years) & 97 (0-3 years) \\
\hline & 7 (4-7 years) & 59 (4-7 years) \\
\hline & 5 (8-14 years) & 41 (8-18 years) \\
\hline
\end{tabular}

\section{Research question \#1}

Can cognitive maps inform us about how this sample of women organized their thoughts relative to vulnerabilities and triggers that anteceded their crimes? On an aggregate (group) level, the cognitive maps of the fatal and nonfatal abusers were similar. They shared common underlying struc- 
tures consisting of three disparate clusters inductively labeled "Family Intimacy", "Negative Emotion" and "Abuse" (see Figure 2).

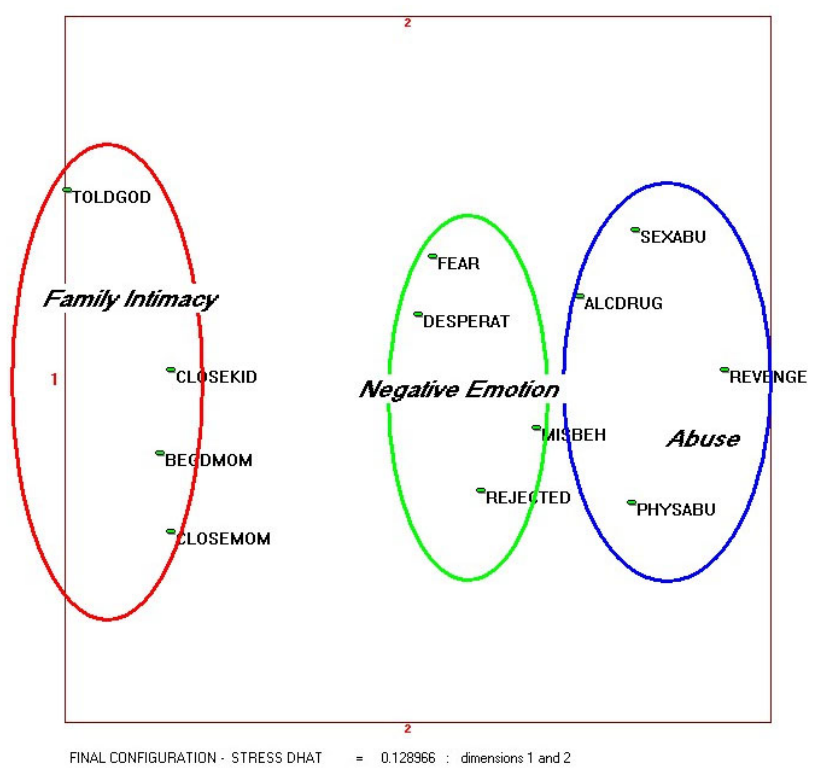

Figure 2. Total similarity map

The cluster labeled Family-Intimacy consists mainly of the items signifying relational closeness (Being a Good Mom, Close to Child, and Close to Mom) but also the distinctly religious (but for many, marginal) item Told by God to the left. A significant divide separates this cluster from a cluster in the center labeled Negative Emotion, which includes the items: Fear, Desperation, Rejected, and Misbehave. The third cluster labeled Abuse consists of Sexual Abuse, Physical Abuse, Revenge, and Alcohol/Drug Use. The following is an exploration of how specific risk factors or groups of them operate in the maps based on extant literature and clinical experience of the authors.

\section{Cluster One: Family Intimacy Close to mother}

Narratives of participants suggest they experienced disorganized attachment with their caregivers. There is growing literature addressing the relationship between abnormal parenting, disorganized attachment and risks for later psychopathologies. Disorganized attachment is often rooted in the inconsistent behavior of a parent that vacillates from generating fear to providing reassurance thereby producing both alarm and comfort in a vulnerable child. ${ }^{[27-30]}$ These dynamics make it difficult for the child to form a coherent, interactive IWM. Illicit substances used in the participant's homes during formative years affected that adult's ability to provide basic needs including a stable environment and feelings of safety. The participants were conflicted as to how their mothers could express intense, seemingly unconditional love and yet still be either the perpetrator of horrible abuses or a bystander who allowed the abuses to occur. The imbalance of power coupled with sporadic abusive behavior led some participants to use denial or distancing from the abuse for emotional self-protection. ${ }^{[31]}$ This traumatic bonding was in stark contrast to the images of mothers in the media who exuded adoration and tenderness toward their children with whom they interacted seamlessly. Those mothers were always smiling, pleasant, and patient, and the child was without exception, receptive and interactive. The images produced inner conflict between what many participants experienced as children, what they desired in the maternal role and their capacity to manifest their desires.

\section{Being a good mom and close to child}

The maternal role is a "complex cognitive and social process which is learned, reciprocal and interactive". ${ }^{[31]}$ Role attainment is a process by which mothers achieve competence and is influenced by the cultural and family context and by mother and infant traits and characteristics. ${ }^{[14]}$ Mothers with unresolved loss and abuse issues may have altered perceptions of their child's needs. The capacity for maternal insight involves the ability to see things from the child's perspective, to be open to new information, and to be able to consider a complex view of the child. ${ }^{[32]}$ Traumatic experiences bled into the participant's relationship with their children. Some women felt stress related to the pressure of trying to be a "good mother" while lacking sufficient validation, experiencing feelings of social devaluation, or lacking an appropriate maternal role model. ${ }^{[33,34]}$ Some of these women idealized motherhood as the ultimate physical and emotional achievement in their lives. Many interviewed still clung to and measured themselves against the concept of an ideal mother although few were capable of providing descriptions of positive attachment experiences with their own children.

\section{Told by God}

The women's spiritual relationship with God paralleled that of their own mother. There was reverence for God, but some confusion as to why such hardship was allowed to take place in their lives with little reprieve. A few women thought that God told them to kill their children. This was a reflection of religiosity, a morbid concern for religion which when investigated, reveals a basic disturbance in personality. ${ }^{[35]}$ Religiosity is not the same as being devout. A substantial number of individuals who demonstrate religiosity have an authoritarian orientation and a childhood history of abuse and/or neglect. ${ }^{[36]}$ A focus away from self to a powerful other can endorse an insecure sense of safety and support. 
This powerful "other" was interpreted by participants as both putative and a source of strength. It compounded feelings of insecurity and fear in light of an already fragmented self. Religion has the capacity to explain unusual or unfamiliar happenings and is used by some vulnerable women as a rationalization or verbal structure for their illness and otherwise inexplicable behaviors. ${ }^{[35,36]}$

\section{Cluster Two: Negative emotion}

The cluster in the center of the map labeled Negative Emotion consists of the items: Fear, Desperation, Rejected, and Misbehave. Fear, desperation and misbehaving are factors conducive to hurting a child that stem from a loss of hope and surrender to despair experienced by those who lack the fortitude to withstand the enormous pressures of parenting a young child. Meyer \& Oberman ${ }^{[37]}$ stated, "By definition, parenting requires tremendous energy, endurance, and maturity. If one combines preexisting vulnerabilities of a woman who has been abused with the challenges of parenting in socially isolated and economically vulnerable circumstances, the fact that some small number of mothers abuse and even kill their children might seem inevitable." (p. 14)

Many women expressed overwhelming feelings of rejection by both their caregivers and by their children. Perceived rejection by a child can echo that experienced by a woman during her formative years with her own caregiver and can invoke the same rage, anxiety and depression. ${ }^{[28]}$ The perceived threat from the child is "you are nothing, you mean nothing" which mirrors the mother's poor self-concept and causes her great pain. ${ }^{[27,28]}$

\section{Cluster Three: Abuse}

The cluster labeled Abuse consists of Sexual Abuse, Physical abuse, Revenge, and Alcohol/Drug Use. Revenge has deep roots in early conflicts, traumas, and humiliations such as physical and sexual abuse at the hands of parents, siblings, and others. During formative and adult years vulnerable individuals are at risk for developing substance abuse issues to ward off emotional pain and mental health issues including post-traumatic stress disorder, depression, and anxiety. Illicit substances are used to soothe or numb feelings of anxiety and pain and to block unpleasant memories and current realities. $^{[8,27]}$

\section{Cognitive map summary}

Health care providers have been slow to recognize and give adequate attention to the far-reaching consequences of interfamilial violence, particularly that of parents toward their children. ${ }^{[6,27]}$ The Family Intimacy cluster reveals that adverse behavior within families tends to perpetuate itself from one generation to the next. Participants who were abusive experienced significant maltreatment during their formative years, which disrupted any potential for healthy family intimacy. The Negative Emotion cluster appropriately follows reflecting responses of those caught in the pandemonium of intergenerational abuse.

Emotional pain suffered by victims of abuse is imprinted in their minds even if they are no longer vulnerable to their abusers. The Abuse cluster was fittingly positioned after the Negative Emotion cluster in that one of the primary causes of addiction is negative and unregulated emotions. Emotional pain, which in these cases was a byproduct of abuse, can incite the use of illicit substances in an effort to self-soothe, self-medicate. Enacting the full cycle of victimization/abuse only led this sample of women to greater feelings of despair for which many but not all, were regretful. ${ }^{[38,39]}$

\section{Research question \#2}

Do the two groups evaluate the relative importance of the vulnerabilities and triggers differently? This section moves from respondents' judgments of the relative similarity of the vulnerabilities and triggers to their judgment of the relative importance; from the cognitive focus of considering relative similarity to the evaluative focus of relative importance. Rankings of importance provided some insight into how the items presented may have contributed to filicide or abuse from the mother's perspective (see Tables 3 and 4). Of note, the definition of these terms among participants was markedly similar. The two groups diverged to a degree regarding which concepts had the most profound impact on their thinking and behavior. The top three items chose by the mothers incarcerated for killing their children as having the most profound impact upon them were Close to Mom, Being a Good Mom, and Desperate.

Alcohol/Drug Use was ranked first for women incarcerated for abuse and sixth for those incarcerated for filicide. In other words, the large majority of women reported being exposed to alcohol and/or drug use as children, but the group of abusers rankings indicated that substance abuse had the most profound impact on their thinking and behavior. Close to Mom was ranked first for women who committed filicide, but sixth for abusers. Forty-two of the 43 women who committed filicide claimed they currently had very close relationships with their own mothers, and the bond strengthened after the women were incarcerated. The concept of Physical Abuse appeared to be far more characteristic of women who killed their children than the abusers. In fact, it was not listed as a priority of abusers, although they were all incarcerated for charges that included physical abuse of their children. In the rankings of importance, the terms that showed the greatest discrimination between groups were Close to Mom and Physical Abuse (Filicide > Abuser) and Alcohol/Drug Use

ISSN 1925-4040 E-ISSN 1925-4059 
(Abusers > Filicide). The women who committed filicide felt dynamics in the relationship with their mother and the physical abuse endured had the most profound impact on their thinking and behavior whereas women incarcerated for abuse felt that exposure to illicit drugs and alcohol profoundly impacted their thinking and behavior.

Table 3. Participant priority evaluation, $\mathrm{F}=$ Filicide, $\mathrm{A}=$ Abusers

\begin{tabular}{|c|c|c|}
\hline \multicolumn{3}{|c|}{$\begin{array}{l}\text { Please list the top three events that had the most profound } \\
\text { Impact on your thinking and behavior }\end{array}$} \\
\hline & Filicide & Abusers \\
\hline One & Close to mom & Alcohol/Drug Use \\
\hline Two & Being a good mom & Being a good mom \\
\hline Three & Sexual Abuse & Desperate \\
\hline
\end{tabular}

Table 4. Participant priority rankings, $\mathrm{F}=$ Filicide, $\mathrm{A}=$ Abuse

\begin{tabular}{ll}
\hline \multirow{2}{*}{ Concepts } & Rankings \\
\cline { 2 - 2 } & (F:A) \\
\hline Being a good mom & $1(36: 36)$ \\
Alcohol/Drug Use & $2(4: 24)$ \\
Sexual Abuse & $3(3: 5)$ \\
Close to Your Mom & $4(1: 6)$ \\
Close to Your Child & $5(5: 4)$ \\
Physical Abuse & $6(4: 11)$ \\
\hline
\end{tabular}

\section{Stability of survey concepts}

The test-retest survey items demonstrated adequate stability with intraclass correlations of 0.93 (1st pair) and 0.87 (2nd pair).

\section{Limitations}

There are several limitations to the study. It was difficult to access this population of women. The amount of time afforded for the interviews made constraints on methods mandatory to accomplish the endeavor at all. The extent to which the findings are generalizable is unknown and will have to be determined in a larger scale study with a more representative sampling. Because this was a cross-sectional study, direct causal relationships cannot be determined. Although the inmates were advised that participation in the study would be of no direct benefit to them, some of the evaluative responses could have been self-serving or the result of how the mothers have morally justified their crimes. In addition, the very act of measuring any cognitive operation may influence that which is being measured. It is also difficult to ascertain how much of the cognitive process responses to the scale can really reveal. Problems of intrusion, retrospection, and repressed memory would all affect participant responses.
Although care was taken to ensure content validity, it is possible that a different investigator would have arrived at a different set of concepts.

\section{Conclusion}

Despite these limitations, the value of this study is that it describes the cognitive maps of women who fatally and nonfatally abused their children. The evaluative piece shows how the women prioritized factors believed to predispose them to abuse. A way to understand the characteristics of these vulnerable women, with whom health care providers often come in contact, is to describe their beliefs and priorities. The study accomplished this fundamental task and underscored the importance of early identification of women at risk for either fatally or non-fatally abusing their children.

The findings provide insight for those who work with and advocate for women and children at risk including psychologists, social workers and counselors, healthcare providers (e.g., pediatricians, family medicine, women's health, emergency medicine personnel, nurse practitioners and physicians assistants) and community health workers. It underscores that children who are abused but not killed may experience trauma that shapes future perceptions, behaviors and capacity to function in adulthood. The more information gathered in various forms-in this case visual representations, prevention of tragic and unnecessary outcome is more tenable. Enhanced community education that expands beyond biological parents and grandparents regarding potential danger and implications of abusive incidents may facilitate more expedient reporting of children in at-risk homes. The design and implementation of more effective prevention initiatives can be put in place.

Future investigation will involve a larger population of women and their individual differences explored in more depth. Of interest to the investigators is examination of case-controlled studies examining features of filicide victims whose mothers were reported to child protective services for abuse compared to those of abused children who are not killed. The findings could point to characteristics that may identify women who are at high risk for killing their children.

While research on resilient children is growing, more knowledge is needed concerning individuals abused during formative years who do not become abusive parents. Have these individuals decided not to become parents, have they become overly indulgent parents, adequate parents, etc.? Or, are they abusive parents who have not been identified? We also know little about children who were not abused, yet grow up to become abusive parents. Further information related to these populations is critical if the intergenerational transmission of 
abusive parenting is to be adequately tested.

Both fatal and nonfatal abuse was triggered by a preponderance of risk factors and a relative absence of supports or compensatory factors. Their ability to seek and obtain effective assistance was impaired by their inability to elicit relief from victimization as children. Multidimensional scaling extracted links that the women were unable to make on a conscious level when responding to content analysis questions and during conversations with the investigator. The method demonstrated that the thought process of this population of women is more complex than the literature suggests. Because children suffer from fatal and nonfatal child abuse every day, the issue commands powerful intellectual capital to ameliorate its devastating consequences. One approach is to consider from the standpoint of the mother, the intercon- nectivity of potential vulnerabilities and triggers, not only in terms of the women's explicit understanding of those factors, but of the latent associations made between them.

\section{ACKNOWLEDGEMENTS}

I would like to express my heartfelt gratitude to A.P.M. Coxon, PhD, Honorary Professorial Research Fellow Graduate School of Social and Political Studies without whom this project would not have been completed. His remarkable intellect, capacity for kindness and good humor remains an inspiration to me. He was truly an outstanding colleague, mentor and friend to whom I am deeply grateful. Dr. Coxon died February 7, 2013.

\section{CONFLICTS OF INTEREST DisClOSURE}

The authors declare that there is no conflict of interest.

\section{REFERENCES}

[1] Williams J. Learning without awareness. Studies in Second Language Acquisition. 2005; 27: 269-304. http://dx.doi.org/10.1017/S 0272263105050138

[2] Hatters SF, Horwitz S, Resnick PJ. Child murder by mothers: A critical analysis of the current state of knowledge and a research agenda. American Journal of Psychiatry. 2005; 162(9): 1578-1587. PMid:16135615 http://dx.doi .org/10.1176/appi .ajp.162 . 9.1578

[3] McKee GR. Why mothers kill: A forensic psychologist's casebook New York, NY: Oxford University Press. 2006. http://dx. doi.o rg/10.1093/med:psych/9780195182736.001.0001

[4] Resnick PJ. Child murder by parents: A psychiatric review of filicide. American Journal of Psychiatry. 1969; 126(3): 73-82. PMid:5801251 http://dx.doi.org/10.1176/ajp.126.3.325

[5] U.S. Department of Health and Human Services, Centers for Disease Control, National Center for Health Statistics. Center for Disease Control and Prevention, Child Maltreatment: Risk and Protective Factors. 2013. Available from: http://www.cdc.gov/violenceprevention/childmaltre atment/riskprotectivefactors.html

[6] Bowlby J. Attachment. Basic Books, 1969. PMid:4890814

[7] McCarthy MC, Lumley MN. Sources of emotional maltreatment and the differential development of unconditional and conditional schema. Cognitive Behavioral Therapy. 2010; 41(4): 288297. PMid:22471813 http://dx.doi .org/10.1080/16506073. 2012.676669

[8] SAMHSA'S Concept of Trauma and Guidance for Trauma Informed Care. Prepared by SAMHSA's trauma and justice strategic initiative. 2014; Available from: file:///Users/marie/Downloads/Sam hsa\%20Trauma-informed\%202014.pdf .5t=-- PMid: 18548348

[9] Crouch JL, Risser HJ, Skowronski JJ, et al. Does accessibility of positive and negative schema vary by child physical abuse risk? Child Abuse and Neglect. 2010; 34(11): 886-895. PMid:20888638 http://dx.doi.org/10.1016/j.chiabu. 2010.05.005

[10] Farc M, Crouch J, Skowronski J, et al. Hostility ratings by parents at risk for child abuse: Impact of chronic and temporary schema activa- tion. Child Abuse and Neglect. 2008; 32: 177-193. PMid: 18316122 http://dx.doi.org/10.1016/j.chiabu.2007.06.001

[11] Bugental D, Johnston C. Parental and child cognitions in the context of the family. Annual Review of Psychology. 2010; 51: 315344. PMid:10751974 http://dx.doi.org/10.1146/annurev.p sych.51.1.315

[12] Azar S, Weinzierl K. Child maltreatment and childhood injury research: A cognitive behavioral approach. Journal of Pediatric Psychology. 2009; 30(7): 598-614. PMid:16166248 http://dx.doi.o $\mathrm{rg} / 10.1093 /$ jpepsy/jsi046

[13] Seng A, Prinz R. Parents who abuse: What are they thinking? Clinical Child Family Psychology Review. 2008; 11: 163-175.

[14] Mercer RT. Becoming a mother versus maternal role attainment. Journal of Nursing Scholarship. 2004; 36(3): 226-232. http://dx. doi . org/10.1111/j.1547-5069.2004.04042.x

[15] Sammons RA. Psychotic mothers who kill their children. Paper presented at the semiannual forensic symposium of the Institute of Law, Psychiatry, and Public Policy, Charlottesville, VA. 1987.

[16] van der Kolk BA. Developmental trauma disorder: Toward a rational diagnosis for children with complex trauma histories. Psychiatric Annals. 2005; 35(5): 401-408.

[17] Mugavin M. Maternal filicide theoretical framework. Journal of Forensic Nursing. 2008; 4: 68-79. PMid:18522605

[18] Haggard-Gran U, Hallquist J, Langstrom N, et al. The role of alcohol and drugs in triggering criminal violence: A case-crossover study. Addiction. 2006; 101(1): 100-108. PMid:16393196 http: //dx.doi.org/10.1111/j.1360-0443.2005.01293.x

[19] Roelofs J, Lee C, Ruijten T, et al. The mediating role of early maladaptive schemas in the relation between quality of attachment relationships and symptoms of depression in adolescents. Behavioral Cognitive Psychotherapy. 2011; 39(4): 471-479. PMid:21418710 http://dx.doi.org/10.1017/S1352465811000117

[20] Sturge-Apple ML, Suor JH, Skibo MA. Maternal child-centered attributions and harsh discipline: the moderating role of maternal working memory across socioeconomic contexts. Journal of Family Psychology. 2014; 28(5): 645-654. PMid:25221969 http: //dx.doi.org/10.1037/fam0000023 
[21] Ertem IO, Leventhal JM, Dobbs S. Intergenerational continuity of child physical abuse: how good is the evidence? Lancet. 2000 Sep 2; 356(9232): 814-9. http://dx. doi .org/10.1016/S0140-673 $6(00) 02656-8$

[22] Widom CS, Czaja SJ, DuMont KA. Intergenerational transmission of child abuse and neglect: Real or detection bias? Science. 2015; 347(6229): 1480-1485. PMid:25814584 http://dx.doi.org/10. $1126 /$ science. 1259917

[23] Institute of Medicine of the National Academies. Ethical considerations for research involving prisoner. The National Academies Press, Washington, D.C. 2006.

[24] Mugavin M. Similarity Judgment Scale [Measurement Instrument]. 2005.

[25] Lynn M. Determination and quantification of content validity. 1986; 35: 382-386

[26] Nunnally J, Bernstein I. Psychometric theory. 3rd Ed. New York: McGraw-Hill, Inc., 1994.

[27] Herman JL. Trauma and recovery. New York, NY: Basic Books. 1997.

[28] Main M, Hesse E. Parents' unresolved traumatic experiences are related to infant disorganized attachment status: Is frightened and/or frightening parental behavior the linking mechanism? In M. Greenberg, D. Cicchetti, \& E. M. Cummings (Eds.), Attachment in the preschool years: Theory, research, and intervention. Chicago: University of Chicago Press. 1990: 161-184.

[29] Parlar M, Frewen P, Nazarov A, et al. Alterations in empathic responding among women with posttraumatic stress disorder with childhood trauma. Brain Behavior. 2014; 4(3): 381-9. PMid:24944867 http://dx.doi.org/10.1002/brb3.215

[30] Padilla PP, Calvete E. Cognitive vulnerabilities as mediators between emotional abuse and depressive symptoms. Journal of Abnormal Child Psychology. 2014; 42(5): 743-53. PMid:24292965 http://dx.doi.org/10.1007/s10802-013-9828-7
[31] Koniak-Griffin D. Maternal role attainment. Image: Journal of Nursing Scholarship. 1993; 25(3): 257-262. http://dx.doi.org/10. 1111/j.1547-5069.1993.tb00791.x

[32] Oppenheim D, Koren-Karie N. Mothers' insightfulness regarding their children's internal worlds: The capacity underlying secure childmother relationships. Infant Mental Health. 2002; 23(6): 593-605. http://dx.doi.org/10.1002/imhj.10035

[33] Murray L, Finn M. Good mothers, bad thoughts: New mothers' thoughts of intentionally harming their newborns. Feminism Psychology. 2012; 22(1): 41-59. http://dx.doi.org/10.1177/09593 53511414015

[34] Phoenix A, Woollett A. Motherhood: Social construction, politics, and psychology. In A. Phoenix, A. Woollett, \& E. Lloyd (Eds.), Motherhood. London, England: Sage Publications. 1991; 12-28.

[35] Kendler K, Liu X, Gardner C, et al. Dimensions of religiosity and their relationship to lifetime psychiatric and substance use Disorders. Am J Psychiatry. 2003; 160: 496-503. PMid:12611831 http://dx.doi.org/10.1176/appi.ajp.160.3.496

[36] Hackney C, Sanders G. Religiosity and mental health: A meta-analysis of recent studies. Journal for the Scientific Study of Religion. 2003; 42(1): 43-55. http://dx.doi.org/10.1111/1 468-5906.t01-1-00160

[37] Meyer CL, Oberman M. Mothers who kill their children: Understanding the acts of moms from Susan Smith to the "Prom Mom". New York: New York University Press. 2001.

[38] Crimmins S, Langley S, Brownstein HH, et al. Convicted women who have killed their children: A self-psychology perspective. Journal of Interpersonal Violence. 1997; 12(1): 49-69. http://dx. doi . org/10.1177/088626097012001004

[39] Eisenberg N, Spinrad T, Eggum N. Emotion-related self-regulation and its relation to children's maladjustment. 2010. NIH Public Access. Available from: http://www.ncbi.nlm.nih.gov/pmc/art icles/PMC3018741/ 